\title{
ÉTICA DAS PESQUISAS QUALITATIVAS SEGUNDO SUAS CARACTERÍSTICAS
}

\section{ETHICS OF QUALITATIVE RESEARCH ACCORDINS TO ITS CHARACTERISTICS}

\author{
Maria Cecilia de Souza Minayo ${ }^{1}$
}

\begin{abstract}
Resumo: Este ensaio trata da ética em pesquisa qualitativa e ressalta seu caráter compreensivo, relacional e reflexivo, assim como as vantagens e os problemas que advêm dessa forma de conhecimento. O texto se divide em duas partes. Na primeira apresentam-se mudanças trazidas pela Resolução do Conselho Nacional de Saúde de no. 510/2016 em relação às Resoluções anteriores, adequando prescrições e demandas do Conselho Nacional de Ética em Pesquisa (CONEP) e dos Comitês de Ética em Pesquisa (CEP) à filosofia e à prática das Ciências Humanas e Sociais (CHS). A segunda parte aprofunda uma análise sobre os fundamentos da Ética da Pesquisa em CHS e trata das relações entre pesquisador-pesquisado e sua reflexividade; as formas de abordagem e os dilemas da pesquisa empírica; e as diferenças epistemológicas entre verdade, aproximação e possibilidade de generalização. O texto conclui ressaltando a importância da pesquisa em CHS e, em particular, da pesquisa qualitativa.
\end{abstract}

Palavras-chave: Pesquisa qualitativa; Ética; Reflexividade; Teoria do conhecimento.

Abstract: This essay deals with ethics in qualitative research and highlights its comprehensive, relational and reflective character, as well as the advantages and problems that arise from this form of knowledge. The text is divided into two parts. The first presents changes brought about by the Resolution of the National Health Council of no. 510/2016 in relation to previous Resolutions, adapting the requirements and demands of the National Research Ethics Council (CONEP) and the Research Ethics Committees (CEP) to the philosophy and practice of the Humanities and Social Sciences (CHS). The second part deepens an analysis of the foundations of Research Ethics in CHS and deals with the relationship between researcher-researched and their reflexivity; the approaches and dilemmas of empirical research; and the epistemological differences between truth, approximation and the possibility of generalization. The text concludes by highlighting the importance of research in CHS and, in particular, of qualitative research.

Key words: Qualitative research; Ethics; Reflexivity; Theory of knowledge.

\section{Introdução}

Este artigo tem dois propósitos: o primeiro é apresentar o histórico e a concretização das diretrizes éticas exaradas pelo Conselho Nacional de Saúde para pesquisas no campo das ciências humanas e sociais; e em seguida, dentro do conceito de filosofia antropológica, fazer uma discussão mais ampliada sobre ética enquanto postura e prática de investigação, em especial, nas pesquisas qualitativas.

As diretrizes brasileiras para análise dos aspectos éticos das pesquisas com seres humanos primeiro foram apresentadas na Resolução no. CNS no. 196/96 que, em 1996

\footnotetext{
${ }^{1}$ Doutorado em Saúde Pública pela Fundação Oswaldo Cruz (FIOCRUZ). Fundação Oswaldo Cruz, Escola Nacional de de Saúde Pública (FIOCRUZ), Rio de Janeiro, RJ, Brasil. E-mail: maminayo@ terra.com.br
} 
instituiu a Comissão Nacional de Ética em Pesquisa- CONEP da qual derivaram os vários Comitês de Ética locais e institucionais. Esse primeiro dispositivo foi depois aperfeiçoado por meio da Resolução CNS no. 466/2012.

Tradicionalmente, as comissões e comitês de ética, foram criados pela demanda dos governos e da sociedade, por causa das formas como a produção do conhecimento em algumas áreas, particularmente, na medicina, vinha ocorrendo no mundo, frequentemente com total desrespeito à liberdade, ao corpo das pessoas, a suas vontades, a seus interesses e a sua vida. Os exemplos desses avanços antiéticos são muitos, como os experimentos usando e abusando de pessoas vulneráveis. Por isso e em reação, o primeiro campo que estabeleceu comitês reguladores foi o da biomedicina. Uma vez criados, os mesmos procedimentos foram exigidos para tratar todo tipo de pesquisa com seres humanos, criando-se uma inevitável tensão com os cientistas sociais, por causa da inadequação de uma pretensa homogeneidade científica.

A bioética tradicional fundamenta-se na filosofia pragmática que visa a situar o pensamento o mais próximo possível dos problemas práticos, por considerar que o ser homem e o mundo constituem uma unidade (RORTY, 1994). Neves (2006) elaborou uma extensa pesquisa sobre os fundamentos anglo-americanos do pragmatismo bioético. De acordo com essa autora, suas bases assumem uma posição segundo a qual, o critério de utilidade é a principal definição da moralidade de uma ação. A autora afirma que há um sentido relativista na razão anglo-americana, desenvolvido em casuísticas e em situações que exigem decisão ética. Normas para conduta moral são vistas para serem obedecidas, contribuindo para o elevado sucesso dessa perspectiva na área da clínica. De acordo com Neves, a presença de bioeticicistas na rotina das instituições de saúde norte-americanas mostra o funcionalismo e o tecnicalismo da bioética. Nesse tipo de ação normativa, as bases teóricas coincidem com as próprias normas.

A crítica humanista à bioética de tipo anglo-americano pode ser resumida em dois pontos: (1) a parcialidade na forma como a pessoa é considerada; (2) e a supervalorização do ser humano como sendo racional e dono de seu próprio desejo, colocando ênfase em sua inclinação individualista.

A literatura das CHS desde o início mostra o desconnforto dos cientistas sociais e das áreas de humanidades com as imposições generalizantes exaradas pela biomediicina. Seu desconforto vai desde uma espécie de revolta contra as exigências descabidas - é o caso de Hammersley (2009), que escreveu um artigo cujo título é "Against the ethicists: The evil of ethical regulation", a esforços para esclarecer as diferenças (ISRAEL; HAY, 
2006), passando pelo empenho em estabelecer e comparar os princípios diversos, até a oficialização de procedimentos específicos por autoridades de diversos países, como Estados Unidos, Canadá, Reino Unido, Nova Zelândia, Austrália e outros, como se pode ler nos textos de Guerriero (2006); Victora e Oliven (2004); Social Science and Humanities Research Ethics Special Working Committee: Giving voice to the Spectrum (2004); The Indian Committee for Ethics in Social Science Research in Health: ethical guidelines for social research in health (2001); Ethics committee for Social Sciences and Humanities (SSH) from European Union (2021), Guerriero e Minayo (2016), Minayo e Guerriero, 2019, dentre outros.

No Brasil, ambas já citadas resoluções tiveram como referência documentos internacionais sobre o tema, incluindo o Código de Nuremberg (1949), a Declaração de Helsinki (1964) e as diretrizes propostas pelo Council for International Organizations of Medical Sciences (CIOMS, 1993). Essas últimas foram elaboradas por associações médicas e tinham como alvo pesquisas biomédicas, comportamentais (leia-se ciências humanas e sociais) e epidemiológicas, ou seja, pretendiam abranger todas as áreas do conhecimento.

Como em todo o mundo, logo depois da promulgação das normas e instituição de comitês, os cientistas brasileiros das áreas de humanidades e sociais começaram a se manifestar, ressaltando as limitações dos procedimentos para as pesquisas que adotam paradigmas compreensivos, interpretativos e críticos. Tais incompatibilidades foram endereçadas à Comissão Nacional de Ética em Pesquisa (CONEP) da qual derivam os vários Comitês de Ética (CEP) locais e institucionais.

Demorou muito tempo e ocorreram muitos conflitos até que a comunidade dos Cientistas Sociais e das áreas de Humanidades conseguisse ver publicada, no Brasil, a Resolução CNS 510/2016, uma espécie de código ético para pesquisas escrita por eles. Essa aprovação ocorreu no Plenário do Conselho Nacional de Saúde, em sua XXX Reunião Ordinária, realizada nos dias 6 e 7 do mês de abril de 2016 (CNS, 2016), que deliberou, usando suas atribuições conferidas pela Lei $\mathrm{n}^{\circ}$ 8.142, de 28 de dezembro de 1990.

\section{Importância da Resolução CNS no. 510/2016}

A Resolução no 510/2016 é uma novidade importante para o campo científico brasileiro, pois ela reconhece oficialmente o papel diferenciado das CHS e de seus 
métodos nas pesquisas com seres humanos, em particular, as que são realizadas na área da saúde. A expectativa é que essa resolução colabore também para que o Sistema CEP/CONEP trate todos os pesquisadores com a mesma consideração, pois não cabe a ele tomar partido na definição do que seja ciência. A Resolução $\mathrm{n}^{\circ} 510$ está em vigor desde maio de 2016. Garantir o texto foi um avanço, mas não foi tudo. Como já afirmado em Guerriero e Bosi (2015), é importante desencadear um processo de efetivação de tais diretrizes, o que engloba dois aspectos fundamentais: primeiro, a construção de uma nova cultura no interior da CONEP e dos mais de 800 CEP brasileiros e na comunidade acadêmica; o segundo, a necessidade de uma ação comunicativa em vários outros planos. Desde já é preciso deixar claro que, embora em vigor, a Resolução 510/2016 ainda está sendo muito pouco usada, inclusive pelos cientistas sociais e pelos que fazem pesquisa qualitativa.

Em artigo sobre o assunto, Iara Guerriero - que foi a presidente da Comissão que elaborou o texto - e Minayo (2016) - que foi consultora - ressaltam que a Resolução determina diretrizes éticas específicas para as ciências humanas e sociais (CHS) e é resultado de anos de trabalho de pessoas e instituições que há muito apontam a inadequação de uma única orientação de cunho biomédico para pesquisas em diferentes áreas. Nesse texto, as autoras discutem as principais diferenças entre a pesquisa em CHS e a pesquisa biomédica. E mostram como a disputa pelo poder de definir o que é ciência caracteriza o campo científico, tema que atravessa o mundo acadêmico há mais de um século, mas não deveria caber à Comissão Nacional de Ética em Pesquisa, cuja missão é proteger os participantes das pesquisas.

\section{Seis mudanças da resolução do CNS no. 510/2016 em relação à do CNS no. $466 / 2012$}

A Resolução no. 510/2016 se aplica a toda pesquisa que se inclua na seguinte definição, escrita no seu art. 2: "aquelas que se voltam para o conhecimento, compreensão das condições de existência, vivência e saberes das pessoas e dos grupos, em suas relações sociais, institucionais, seus valores culturais, suas ordenações históricas e políticas e suas formas de subjetividade e comunicação, de forma direta ou indireta, incluindo as modalidades que envolvem intervenção".

Neste texto, seguindo o caminho de Guerriero e Minayo (2016), foram selecionadas seis mudanças que a Resolução no 510/2016 traz em relação à no 466/2012: 
definição do que não precisa ser avaliado pelo Sistema CEP/CONEP; discernimento entre processo e registro de consentimento e assentimento livre e esclarecido; avaliação de mérito científico; explicitação das etapas que antecedem ao projeto completo; relação entre a Resolução n ${ }^{\circ} 510$ e a 466; e composição do Sistema CEP/CONEP.

Situações em que as pesquisas não necessitam passar por comitê de ética - Os casos estão previstos no parágrafo único do art. $1^{\text {o }}$ : (1) Pesquisa de opinião pública. Por exemplo, investigação sobre intenção de voto, que acontece em espaço público em que o transeunte é convidado a informar sua intenção; (2) Pesquisa que utiliza informações de acesso público, nos termos da Lei n ${ }^{\circ} 12.527$ de 18 de novembro de 2011, segundo a qual todo documento produzido ou sob a guarda do Estado é de natureza pública, a menos que permita a identificação individual ou implique em questões de segurança pública. É o caso de estudos sobre dados do DATASUS, disponíveis inclusive na internet. (3) Pesquisa que utiliza informações de domínio público. Exemplo, as realizadas sobre notícias divulgadas em jornais de grande circulação. (4) Pesquisa censitária de domínio e missão do Instituto Brasileiro de Geografia e Estatística (IBGE). (5) Pesquisa com bancos de dados, cujas informações são agregadas, sem possibilidade de identificação individual. Incluem-se as que não estão disponíveis na internet. (6) Revisão de literatura científica, uma vez que o pesquisador trabalha com artigos, livros e outros materiais já publicados e de domínio público. (7) Pesquisa reflexiva e teórica sobre situações que emergem da prática profissional, desde que não se revelem dados que identifiquem pessoas. (8) Atividade realizada com o intuito de melhorar o processo educativo, o ensino ou treinamento de alunos de graduação, de curso técnico ou de pós-graduação, sem caráter de pesquisa científica. É o caso de entrevistas para treinamento de metodologia de pesquisa qualitativa com finalidade de discussão das técnicas.

Há duas situações previstas na Resolução n ${ }^{\circ}$ 510/2016 em que o art. $1^{\circ}$, item 8 não se aplica, e estão descritas nos $\S 1^{\circ}$ e $\S 2^{\circ}$. O $\S 1^{\circ}$ menciona que não se enquadram no citado inciso os trabalhos de conclusão de curso (TCC), monografias e similares que trabalhem com seres humanos. Os autores devem apresentar os protocolos de pesquisa ao Sistema CEP/CONEP. O $\S 2^{\circ}$ trata de projetos de investigação resultantes do planejamento ou da execução de atividade educacional, ensino ou treinamento. Seus autores devem, de forma obrigatória, apresentar protocolo de pesquisa ao Sistema CEP/CONEP.

Discernimento entre processo e registro de consentimento e assentimento livre e esclarecido - A Resolução n ${ }^{\circ}$ 510/2016 trata do consentimento e do assentimento livre e 
esclarecido no art. 15, que também estabelece diferentes modalidades de registro, respeitando-se a maior diversidade possível e legítima de formas de interação com os participantes das pesquisas. É importante ressaltar que a Resolução não utiliza a palavra "termo", justamente para evitar uma similaridade com pesquisas que trabalhem com outros paradigmas. A palavra "registro" foi escolhida durante o processo de elaboração da Resolução $n^{\circ}$ 510/2016 exatamente para explicitar que há diferenças e especificidades nas pesquisas em CHS. Não cabe, portanto, a referência a Termo de Consentimento Livre e Esclarecido ou a Termo de Assentimento Livre e Esclarecido nos projetos CHS.

Assim reza o art. 15: "o Registro do Consentimento e do Assentimento é o meio pelo qual é explicitado o consentimento livre e esclarecido do participante ou de seu responsável legal, de forma escrita, sonora, imagética, ou outras que atendam às características da pesquisa e dos participantes, devendo conter informações em linguagem clara e de fácil entendimento para o suficiente esclarecimento sobre a pesquisa". O $\S 1^{\circ}$ desse artigo menciona que, quando não houver possibilidade de nenhum registro de consentimento e de assentimento, o pesquisador deve entregar ao participante um documento contendo informações previstas para o consentimento livre e esclarecido, conforme descrito no art.17. Cabe ressaltar que esse documento só é necessário se o processo de consentimento/assentimento livre esclarecido não tiver sido registrado de outra maneira, por exemplo, por gravação sonora, imagética ou por outros meios. No $\S$ $2^{\circ}$, está escrito que "a obtenção de consentimento pode ser comprovada também por meio de testemunha que não componha a equipe de pesquisa", e que acompanhe a manifestação positiva ou negativa do participante do estudo (BRASIL, 2016).

Avaliação de mérito científico - Essa avaliação exige conhecimento da metodologia utilizada no projeto e dificilmente um CEP terá entre seus membros alguém que dê conta da diversidade teórica e metodológica das CHS. Por isso, o art. 25 estabelece que a avaliação a ser feita pelo Sistema CEP/CONEP incidirá somente sobre os aspectos éticos dos projetos, considerando os riscos e a devida proteção dos direitos dos participantes da pesquisa. $\mathrm{O} \S 1^{\circ}$ reza que a avaliação científica dos aspectos teóricos dos projetos submetidos nos termos da Resolução $n^{\text {o }}$ 510/2016 compete a instâncias acadêmicas especificas, tais como comissões científicas, bancas de pós-graduação, instituições de fomento à pesquisa, entre outros. Não cabe ao Sistema CEP/CONEP a análise do desenho metodológico em si. No $\S 2^{\circ}$ está escrito que a avaliação a ser realizada pelo Sistema CEP/CONEP incidirá somente sobre os procedimentos metodológicos que impliquem riscos aos participantes. 
Portanto, não é atribuição do Sistema CEP/CONEP, por exemplo, solicitar o cálculo amostral de uma pesquisa qualitativa. Ou ainda, solicitar o roteiro de entrevista, se o pesquisador informou que ela será aberta e em profundidade. Esses e outros procedimentos equivocados têm sido frequentemente solicitados, com prejuízo para o andamento dos estudos. Não é demasiado repetir que o papel do Sistema CEP/CONEP é, sobretudo, o de proteção ao participante. Por isso, cabe-lhe avaliar se as ações previstas no processo de investigação podem lhe trazer algum dano e solicitar ao pesquisador que adote medidas que possam minimizá-lo.

Etapas preliminares descritas na resolução 510/2016 não precisam de aprovação - O art. 24 da Resolução estabelece que todas as etapas preliminares necessárias para que o pesquisador elabore seu projeto não são alvo de avaliação do Sistema CEP/CONEP. Essa decisão foi necessária porque frequentemente gestores de saúde, por receio de algum dado dos usuários ou do sistema ser vazado, exigiam parecer de ética para aprovar estudos em suas unidades. Isso criava um impasse, porque, de um lado, o investigador precisava de permissão para submeter o projeto ao CEP. De outro, o responsável institucional o exigia antecipadamente.

A Resolução $n^{\circ}$ 510/2016 em seu art. 2 explicita as etapas preliminares para as quais o pesquisador não precisa de licença: (1) atividades para averiguar as condições de possibilidade de realização da pesquisa, por exemplo, um estudo documental; (2) contatos com possíveis participantes sem sua identificação e sem o registro público e formal das informações obtidas; (3) visitas às comunidades, aos serviços e conversas com líderes comunitários e outros; (4) essas ações não se confundem com "estudos exploratórios" ou com "pesquisas piloto", modalidades que devem passar por comissões de ética.

Relação entre a Resolução $n^{o}$ 510/2016 e a Resolução $n^{\circ}$ 466/2012 - O art. 32 da Resolução 510/2016 trata dessa relação. A decisão é que, quando não houver prejuízo ao disposto na Resolução $n^{\circ}$ 510/2016 aplica-se o disposto nos itens VII, VIII, IX e X da Resolução n 466/2012. No parágrafo único do mesmo art. 32 está escrito que, em situações não contempladas pela Resolução $n^{\circ}$ 510/2016, os princípios éticos contidos na Resolução n 466/2012 prevalecem.

Em relação a esse parágrafo, cabe destacar que a minuta da Resolução nº 510/2016 foi elaborada contemplando todos os cuidados presentes na Resolução n ${ }^{\circ}$ 466/2012, na medida em que fossem aplicáveis às pesquisas em CHS. Portanto, se houver lacuna, o correto é aplicarem-se os princípios de autonomia, beneficência, não maleficência, justiça 
e equidade, previstos na Resolução n 466/2012. É claro que princípios não são procedimentos e não devem ser solicitados pelos CEP aos projetos de CHS.

Composição do Sistema CEP/CONEP - Por causa dos múltiplos referenciais teórico-metodológicos das disciplinas que compõem o campo da saúde, é fundamental que os CEP e a CONEP sejam compostos por membros de diferentes áreas. Com relação aos CEP, o art. 26 afirma que a análise dos projetos de pesquisa cobertos pela Resolução n 510/2016 só poderá ocorrer nos comitês que comportarem representação equânime de membros das ciências humanas e sociais e biomédicas. E os projetos de CHS devem ser revistos pelos membros qualificados dentro da área de conhecimento. Segundo o art. 30 da Resolução $n^{\circ}$ 510/2016, deve-se estimular o ingresso de pesquisadores e profissionais atuantes nas CHS nos colegiados dos CEP já existentes e manter a interdisciplinaridade nos que forem criados.

Uma nota importante ao final desta primeira parte é a mobilização da sociedade científica brasileira comprometida com a elaboração da Resolução 510/2016, num processo que se iniciou em julho de 2013 e encerrou suas atividades em março de 2016. O grupo de trabalho criado pela CONEP foi coordenado por Iara Coelho Zito Guerriero - pesquisadora da USP - e reuniu, além de outros membros do CONEP, representantes das seguintes instituições: Departamento de Ciência e Tecnologia do Ministério da Saúde; Associações Científicas e Profissionais de Ensino e Pesquisa em Serviço Social; Associação Brasileira de Psicologia do Desenvolvimento; Associação Nacional de Pesquisa e Pós-Graduação em Psicologia; Associação Brasileira de Psicologia Social; Associação Brasileira de Psicologia Escolar e Educacional; Associação Nacional de História; Associação Brasileira de História Oral; Sociedade Brasileira de História da Ciência; Associação Brasileira de Estudos Sociais das Ciências e das Tecnologias; Associação Brasileira de Pós-Graduação em Saúde Coletiva; Associação Brasileira de Antropologia; Associação Nacional de Pós-Graduação em Ciências Sociais; Fórum de Ciências Humanas e Sociais; Sociedade Brasileira de Sociologia; Conselho Nacional de Pesquisa e Pós-Graduação em Direito; Academia Brasileira de Direito Constitucional; Sociedade Brasileira de Bioética; Associação Brasileira de Editores Científicos; Associação Nacional de Pós-Graduação e Pesquisa em Educação. Maria Cecília Minayo da Fundação Oswaldo Cruz e Sueli Gandolfi Dallari da USP atuaram como consultoras.

Declinar esses nomes reverencia a todas as instituições e pessoas que se dispuseram a colocar a mão nesse vespeiro. Menção muito especial precisa a ser feita a Iara Z.C. Guerriero que coordenou os trabalhos. Os empecilhos para mudança eram 
muitos e persistentes, mas o grupo de trabalho conseguiu o máximo possível de elementos e argumentos para que sua voz fosse ouvida. Mas que fique claro: a visão de ética em pesquisa no Brasil ainda continua muito estreita. No âmbito internacional, vários códigos de ética são mais abrangentes que os brasileiros, seja em relação ao que homogeneiza todas as investigações, seja quanto aos dispositivos para as CHS. A Noruega, por exemplo, dispõe de diretrizes nacionais específicas para as ciências sociais, humanas, jurídicas e teológicas que contemplam o valor e a função social da pesquisa; os interesses da sociedade; a necessidade da liberdade para investigar; o papel e os interesses dos gestores acadêmicos; os princípios e os interesses dentro das comunidades científicas, inclusive em suas relações com os estudantes; a responsabilidade das agências de financiamento; as consequências dos resultados das pesquisas; e a popularização da ciência. Infelizmente nossa visão ainda está muito restrita.

\section{Reflexões imprescindíveis sobre ética em pesquisa qualitativa}

Nesta parte do artigo tento primeiro falar sobre o os fundamentos da investigação qualitativa, suas qualidades e atributos que vão muito além das exigências das normas éticas, não porque elas sejam desimportantes, mas porque são prescritivas. E, a ética da pesquisa qualitativa não se limita a um documento protocolado e aceito pelo CEP, mas se refere ao que há de profundo nesse tipo de conhecimento, nas condições e contingências de acessá-lo, à construção da verdade e aos cuidados possíveis para que os estudos sirvam às pessoas e grupos pesquisados.

Fundamentos - Os fundamentos da investigação qualitativa partem de uma visão humanista que tem origem na fenomenologia (HUSSERL, 2008; HEIDEGGER, 2005) no existencialismo (SARTRE, 1997), na hermenêutica (GADAMER, 2003) na teoria da ação comunicativa e da dialética (HABERMAS, 1987) na teoria das percepções (MERLEAU-PONTY,1999) e outros. Essa visão pode ser resumida no fato de que a singularidade dos sujeitos (das pessoas que entrevistamos, por exemplo) é conformada na intersubjetividade e deve ser entendida na singularidade da pessoa e na universalidade humana que ela porta e na reflexividade de suas ações.

Eu poderia aqui tomar páginas e páginas para descrever esses atributos. Mas utilizarei o pensamento de Levinas (1988) para me ajudar expor o que considero adequado, quando esse autor discute a "ética da alteridade". O autor parte da ideia de que o sujeito só se constrói em comunicação com o OUTRO, entendendo, portanto, a 
intersubjetividade como uma dimensão necessária da subjetividade. Da mesma forma, ressalta que existe uma singularidade em cada realidade concreta, ao mesmo tempo em que qualquer contexto que inclui pessoas faz parte da universalidade das características dos seres humanos. Pontuam-se, portanto, quatro características do ser humano e, em consequência, da ética da pesquisa em CHS, em particular, da pesquisa qualitativa: subjetividade, intersubjetividade, singularidade e universalidade, a serem tratadas simultaneamente.

Levinas (1998) critica o conceito ontológico de sujeito - utilizado pela bioética dizendo que o sujeito não é uma totalidade colocada num pedestal de onde comanda as coisas e as pessoas. Sim, o sujeito é uma obra em construção que ocorre nas inter-relações face a face. Diz o autor que o encontro com o OUTRO promove e conduz um diálogo que pode ir até o infinito em favor da intersubjetividade e destrói não somente a ideia fechada de sujeito como também a centralidade do subjetivismo individualista.

Foco da ética em pesquisa qualitativa - Entendo que, eticamente, fazer uma pesquisa qualitativa empírica não é apenas utilizar um instrumento de observação ou de entrevista adequado, o que poderia ser considerado um tecnicismo. É sim, fazer parte de uma corrente de pensamento e de ação que respeita a singularidade de cada entrevistado ou observado, na certeza de que o conhecimento que ele porta é construído na interlocução intersubjetiva. Logo, é importante entender que as informações que o pesquisador recolhe trazem um tipo específico de verdade, característica da universalidade do ser humano. Ele pode considerar que cada entrevista, por exemplo, traz a história de um sujeito que não se dissolve no OUTRO (nem no pesquisador e nem em qualquer outra pessoa). Na interação propiciada pela ação comunicativa ambos se enriquecem com a proximidade e a compreensão advinda do encontro.

Lévinas (1998) critica os elementos comuns às ciências positivistas presentes na bioética anglo-americana dizendo que (ao pesquisador, ao médico, ao profissional de saúde) não basta ser benevolente com o OUTRO, e sim, aberto para o reconhecimento de

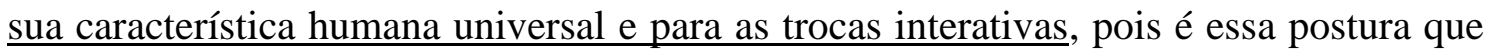
nos faz superar o egocentrismo e a rejeição. E acrescenta que benevolência sem intersubjetividade constitui a mais elevada expressão de dominação do OUTRO e de autoproteção. Referindo-se à ética, o autor ressalta que não é a ontologia que constitui o fundamento da Filosofia, e sim, a relação face-a-face, o encontro com o OUTRO, a intersubjetividade. É nela que o ser humano se constitui, cria seus significados, se enriquece e se torna socialmente responsável. 
Trazendo para o objeto desta discussão, a ética em pesquisa qualitativa consiste em buscar a compreensão do ser humano em sua singularidade; entender sua capacidade intersubjetiva como constitutiva de sua subjetividade (relações e contextos), e sua condição de igualdade de pensar, sentir, expressar-se em palavras e atos e agir com sentimentos e lógica frente aos acontecimentos (universalidade do ser humano e de seu lugar no mundo) (SCHUTZ, 1987). Essa é a tradição teórica humanista, que deve conduzir o pesquisador na compreensão dos problemas dos entrevistados e seus próprios, ao mesmo tempo em que usa procedimentos e busca informações sobre os fenômenos da vida social.

É preciso dizer que o processo ético definido pelos conceitos já explicitados se inicia na definição do objeto e tem seu ponto forte na abordagem metodológica - momento em que se materializa o encontro face a face, e culmina na divulgação das descobertas do trabalho - e culmina na divulgação de seus achados. No caso do método, a despeito de haver muitas teorias e formas de abordagem em campo, sua operacionalização possui elementos comuns que constituem uma espécie de anamnese compreensiva. Nesse tipo de pesquisa, o modelo científico usado para compreender a realidade social sugere (a) uma relação mais próxima possível com OUTRO, sujeito/objeto de pesquisa, levando em conta sua racionalidade, sua intencionalidade, mas também seus sentimentos; e realçando o humano e o universal em qualquer grupo ou ação, ainda que seu lócus de estudo seja uma aldeia, um hospital, uma enfermaria ou um palácio; (b) foco na experiência humana na sua complexidade e singularidade; (c) compreensão do contexto e da história do objeto pesquisado, dando importância aos usos, costumes, crenças, percepções e aos imponderáveis da vida social.

Uma observação muito importante é que subjetividade não é subjetivismo. Por isso a pesquisa qualitativa trabalha não com o conceito de objetividade, mas de objetivação, um conceito trabalhado por Demo (1985), que repousa numa construção que parte da intersubjetividade e utiliza os meios cientíificos corretos para alcançar resultados. Essa objetivação vem, pois, da observância de todo o protocolo para investigação científica, de forma a alcançar o que costumo denominar, a "lógica interna do grupo ou dos atores" pesquisados. Essa lógica não é um achismo, é uma espécie de "rationale" do grupo pesquisadoou do fenômeno que se atinge por uma compreensão profunda e pela crítica das contradições (HABERMAS, 1987), a partir das relevâncias que os atores atribuem a suas palavras, atos, sentimentos, modo de vida, rede de relações e expectativas. É uma tese da pesquisa qualitativa o fato de que todos os seres humanos produzem 
significados, planos, ações e projetos de futuro enquanto constroem o mundo (SCHULTZ, 1987).

Dilemas éticos da pesquisa qualitativa - Neste item sapresento alguns problemas comuns atinentes ao comportamento ético em pesquisa qualitativa. Em primeiro lugar, apesar de todos os atributos já citados, uma pesquisa qualitativa bem desenhada não garante que sua elaboração seja isenta de problemas. A frase de um clássico da antropologia nos lembra de que devemos sempre duvidar de nossas certezas e de nossas verdades quando se trata de uma construção científica qualitativa:

\begin{abstract}
A pesquisa de campo, o lugar onde toda carreira etnológica começa, é a mãe e a ama de leite da dúvida, a atitude filosófica por excelência. A dúvida antropológica (grifo meu) não consiste somente em não saber, mas em se expor o que se sabe ao desconhecido, e sua verdadeira ignorância aos insultos e às negações que afetam as ideias e os hábitos mais caros dos que podem refutá-los no mais alto nível (LÉVY-STRAUSS, 1950: I-XXX).
\end{abstract}

Relação pesquisador-pesquisado - Um dos pontos cruciais da prática em pesquisa qualitativa é a relação do pesquisador com seus interlocutores em campo. Nada é simples. Estudos têm mostrado dois níveis de questões, ambos referentes às características da interação. De um lado, há algumas teorias reprodutivistas - já não muito em voga, mas subsistem - que enfatizam a desigualdade da situação do entrevistado em relação ao investigador como um processo de dominação, uma vez que o pesquisador controla, dirige e guia a interlocução (KANDEL, 1972). O entrevistado (tido como dominado) não é quem toma a iniciativa da pesquisa; os objetivos do estudo, em geral, lhe são desconhecidos; suas chances de conduzir a entrevista são poucas. Esse é um pensamento paralizante. De outro lado, há estudiosos que realçam interação como necessária e frutífera. Embora possa haver conflitos nas relações, consideram que a pesquisa empírica pode ser realizada com espírito de liberdade e reconhecimento do OUTRO e não como uma forma de exploração conforma disserta Lévinas (1998). Por essa razão, esse último grupo trata pesquisadores e pesquisados como sendo ambos responsáveis pelo produto de suas relações e pela qualidade da compreensão da realidade.

Uma premissa básica de ambas as interpretações é que qualquer interação humana significa intervenção na realidade. Portanto, um trabalho de campo não pode ser visto como uma mera coleta de dados, e sim, deve ser entendido como um encontro intersubjetivo que repercute na vida de ambos, pesquisador-pesquisado, o que pode afetar a natureza dos dados. Outro aspecto que não pode ser desconhecido é que a prática empírica ocorre num contexto contraditório e de relações assimétricas. Reconhecer essas assimetrias não significa dizer que as pesquisas sociais precisem cessar, inclusive porque 
as desigualdades na sociedade são muito mais profundas e complexas do que as que ocorrem nas atividades de investigação. O que se recomenda (UNESCO, 2019) é que o significado da investigação, no curto ou no longo prazo, esteja atrelado a um bem maior para a sociedade. E que o grupo pesquisado deva ser contemplado com os resultados do estudo, recebendo retorno de sua participação, da forma mais adequada possível. Em vez da passividade denunciada pelo reprodutivismo, os pesquisadores devem se compreender como parte ativa do processo de construção de um conhecimento aproximado que traga resultados para a sociedade, tão mais fiel à realidade quanto maior for sua interação com o OUTRO (pessoas ou grupos).

Verdade cientítica e conhecimento aproximado - Um segundo dilema ético diz respeito às condições de produção do conhecimento em pesquisa qualitativa, tendo em conta o conceito de "verdade científica". A pergunta é se a comunicação como OUTRO permite objetividade, clareza e transparência, na medida em que o processo ocorre numa relação intersubjetiva. Tais questões foram analisadas em estudos clássicos como os de Goffman (1975), Berreman (1975). Esses autores utilizaram imagens teatrais para mostrar que pesquisador e entrevistado formam um par constituído, simultaneamente, como ator e plateia numa encenação única: numa inter-relação mediada por códigos culturais e por interesses que ambos tentam preservar e proteger. Nas palavras de Goffman são inquestionáveis as dificuldades de comunicação:

Frequentemente descobrimos uma divisão entre uma região interior (grifo
meu), sobre a qual há uma representação rotineira e cuidadosamente pensada;
e a região externa (grifo meu) que é claramente exposta e espontânea. O acesso
a essa região é controlado para que a audiência não veja o que há atrás das
cortinas e para que os estranhos só acessem a representação das cenas (1975,
p.33).

As palavras de Goffman são endossadas por Berreman (1975) que também descreveu as dificuldades que encontrou para acessar informações etnográficas de uma comunidade no Himalaia. Usando as mesmas imagens teatrais, esse autor chama de região interior a parte mais íntima da vida da comunidade. E conclui dizendo que todos os grupos que entrevistou conheciam e guardavam segredos, mostravam seu lado oficial e possuíam estratégias de como se comportar no dia a dia. Ele entendeu que essa coesão ocorre porque, ainda que internamente existam diferenças e conflitos, a existência coletiva depende do grau de coesão, familiaridade e solidariedade, o que implica em compartilhar significados, segredos, zonas proibidas a estranhos e coisas que podem ou não podem ser ditas. Ambos, Goffman e Berreman comentam que há poucas atividades ou relações sociais nas quais as pessoas não estejam envolvidas em práticas incompatíveis 
com as impressões que causam. Ambos chamam atenção para o fato de que a realidade social é um mundo de sombras e luz, no qual todos os atores (inclusive os pesquisadores) escondem e revelam segredos pessoais ou do grupo.

Filósofos como Heidegger (2005) e Gadamer (2003) vão além. Heidegger, olhando filosoficamente para o ser humano, fala da existência de um processo de velamento e de desvelamento na percepção e verbalização do que acontece com qualquer um, não como um processo de ocultamento deliberado, mas como parte do próprio funcionamento do conhecimento do ser humano sobre si mesmo. Ou seja, a história que uma pessoa conta já vem interpretada, embora ela considere que fala a verdade (Heidegger, 2005). Por causa dessas contingências das falas, Gadamer (2003) lembra que o papel do pesquisador não é apenas colher e contemplar a narrativa ou a ação de um interlocutor, porque ele não se esgota na conjuntura em que vive e nem sua ação e pensamento são meros frutos de sua vontade personalidade e desejo. Diz ainda que se cada individualidade é manifestação do viver total, ela não é a totalidade do viver. Ou seja, somos todos parciais, incompletos e marcados pela cultura. Não há escapatória.

É com essa perspectiva de incompletude e de luzes e sombras que a pesquisa qualitativa trabalha. Portanto, o pesquisador qualitativo não lida com a verdade tal qual vista pelas ciências positivistas. E sim, com um conhecimento aproximado cuja qualidade depende de mais, e não de menos inserção no campo, no mundo exterior e interior do entrevistado. A verdade nunca será absoluta e numa será descoberta pelo pesquisador. Corresponderá sempre a sua maior capacidade de aproximação, compreensão e interpretação da realidade, da qual ele próprio faz parte.

Reflexividade - Um terceiro dilema vem do próprio mandato de envolvimento do pesquisador com seu objeto de pesquisa, tema a que os cientistas sociais denominam "reflexividade" (HERTZ, 1997). White (2004) considera que a interação de campo pode modificar a maneira de ver e até de viver de ambos (pesquisador e seu interlocutor) levando à substituição da ação imediata pela ação reflexiva (WHITE, 2004). São conhecidas histórias de antropólogos que se tornaram "nativos" ao realizarem a etnografias das comunidades que estudavam; há casos de alguns que se envolvem até em relações amorosas. A própria amizade entre pesquisadores e interlocutores traz desafios para interpretação dos fatos. Portanto, essa reflexividad suscita questões: o que o pesquisador pode publicar das informações obtidas no contexto de intimidade? O que pode divulgar se sua relação foi superficial e impressionista? Como lidar com os vínculos de lealdade que frequentemente se opõem aos protocolos já conhecidos pela comunidade 
cientifica? São situações que ocorrem na situação de pesquisa, trazem consequências para a cientificidade dos estudos e atravessam toda a história dos trabalhos de campo qualitativos.

Tanto o excesso de intimidade, como a superficialidade ou etnocentrismo das insterpretações levam a uma interpretação equivocada da realidade, como nos casos de Scheper-Hughes (1993) em Death Without Weeping: The Violence of Everyday (1993) texto em que a autora, analisando o excesso de mortalidade infantil no nordeste brasileiro na década de 1970, atribuiu às mães uma espécie de escolha dos filhos que deviam ou não viver, análise absolutamente criticada por outros antropólogos, dentre os quais Nations (2010). E Chagnon em Yanomamö: the fierce people (1968) livro considerado por alguns como uma história maravilhosamente escrita, mas, segundo antropólogos latinoamericanos, ao descrever os Yanomamis violentos e ferozes, o estudo favoreceu o lobby que tentou dividir as terras do grupo a favor de mineradoras e madeireiras. Em alguns trabalhos, os próprios autores fazem crítica sobre a incompletude ou a parcialidade de suas pesquisas em relação ao que disseram os interlocutores, como se lê no texto de Ellis Carol em Emotional and ethical quagmires in returning to the field (1995) e William White em Sociedade de Esquina (2005) Observações mais detalhadas se encontram em Minayo e Guerriero (2014).

Estudiosos muito fiéis ao sentido da intersubjetividade como Schutz (1987) criaram uma categoria "construto de segunda ordem" para ressaltar que o ônus da contextualização e da análise dos dados compete ao pesquisador. $\mathrm{O}$ "construto de segunda ordem" não significa que o texto desdenhe da contribuição dos interlocutores, mas que as falas deles não podem ser tomadas como verdade absoluta. Schutz ressalta mais ou menos o que pensa Gadamer (2003) quando fala sobre a hermenêutica: a narrativa do sujeito é sempre marcada pela sua perspectiva particular e não contém a verdade total sobre os fenômenos em estudo. Ao pesquisador que detém, ao mesmo tempo, o conhecimento empírico amplo construído com a participação de vários interlocutores, a análise do contexto e coloca seu objeto na cena científica nacional e internacional, cabe a compreensão aprofundada da lógica interna que rege o fenômeno ou o grupo estudado.

Em resumo, as controvérsias sobre a verdade, o certo e o errado em abordagens qualitativas sempre existirão. Por isso, o pesquisador, por razões éticas, precisa incluir no texto final de seu estudo, além das descobertas sobre o outro ou o fenômeno que analisa, uma discussão sobre sua situação na interação com seu objeto. 


\section{Conclusões}

A resolução CNS no. 510/2016 constitui um grande avanço para a sociedade brasileira, na medida em que retira amarras de um tipo de ciência que trata das questões humanas e sociais. Para torná-la um dispositivo oficial foram necessários três anos de um grupo de trabalho valoroso, das mais diferentes disciplinas, representando instituições. Os pesquisadores envolvidos tiveram fortes embates epistemológicos com os colegas biomédicos, o que é comum no campo científico, onde as ciências positivistas são dominantes, em detrimento das ciências compreensivas.

Embora a referida Resolução trate dos procedimentos éticos necessários para aprovar propostas de estudos empíricos em CHS, é preciso reafirmar que ética não é "algo" que se injeta num projeto já escrito e nem se reduz a procedimentos. Ao contrário, o conceito de ética em pesquisa deve estar incluído na postura do pesquisador e estar contido na tessitura do texto, desde a definição do objeto até a publicação dos resultados. Embora um comitê só possa agir a partir das informações que tem, o compromisso do pesquisador vai além da conformação técnica de seu trabalho: precisa contemplar o sentido social do estudo, as relações institucionais com os financiadores, a forma de tratar sua equipe - os estudantes nela incluídos - por exemplo, dando crédito a todos os que participam do trabalho. Não menos importante, não deve surrupiar a produção alheia e precisa utilizar corretamente os recursos que recebe.

Por todos os argumentos contidos neste artigo considero que, em geral, as pesquisas qualitativas - em que pesem todos os dilemas e controvérsias - estão fortemente conectadas com os desejos, necessidades, objetivos e promessas de uma sociedade inclusiva e democrática; produzem uma contraposição ao pseudo objetivismo da ciência; integram-se na universalidade dos humanos com os quais compartilham suas riquezas e fraquezas; e se aproximam da verdade junto com as verdades das pessoas e os consensos científicos, excluindo a ideia de verdade essencial e absoluta.

\section{Referências}

BACHELARD, G. Éssai sue la connaissance approchée. Paris: Editions VRI, 1986.

BERREMAN, G. Por detrás de muitas máscaras. In: ZALUAR, A. (org.). Desvendando máscaras sociais. Rio de Janeiro: Editora Francisco Alves, 1975. p. 123-177.

BRASIL. Conselho Nacional de Saúde. Resolução CNS 196/96 trata de diretrizes e normas regulamentadoras de pesquisas envolvendo seres humanos. Brasília: CNS, 1996. 
BRASIL. Conselho Nacional de Saúde. Resolução CNS no 510/2016 determina diretrizes éticas específicas para as ciências humanas e sociais. Brasília: CNS, 2016.

BRASIL. Conselho Nacional de Saúde. Resolução no 466/2012 trata de pesquisas e testes em seres humanos. Brasília: CNS, 2012.

CHAGNON N. Yanomamö: the fierce people. New York: Holt, Rinehart and Winston, 1968.

COUNCIL FOR INTERNATIONAL ORGANIZATIONS OF MEDICAL SCIENCES. International Ethical Guidelines for Biomedical Research Involving Human Subjects. Genève: CIOMS, 1993. Available in: https://cioms.ch/wp-content/uploads/2017/01/WEBCIOMS-Ethica.

DEMO, P. Introdução à metodologia da ciência. São Paulo: Atlas, 1985.

ELLIS C. Emotional and ethical quagmires in returning to the field. Journal of Contemporary Ethnography, [S.I.], v. 24, n. 1, p. 68-98, 1995.

ETHICS COMMITTEE FOR SOCIAL SCIENCES AND HUMANITIES (SSH). European Directives and Horizon. Geneve: 2020 documents. Available in: https://ec.europa.eu/.../hi/h2020_ethics-soc-science-humanities_e...

GADAMER, H. Verdade e método: traços fundamentais de uma hermenêutica filosófica. Petrópolis: Editora Vozes, 2003.

GOFFMAN, E. Strategic interaction. A fascinating study of the espionage games people play. New York: Ballantine Books Co, 1975.

GUERRIERO, I. C. Z. Aspectos éticos das pesquisas qualitativas em saúde. 318 f. 2006. Doutorado (Tese em Saúde Pública) - Faculdade de Saúde Pública, Universidade de São Paulo, São Paulo, 2006.

GUERRIERO, I. C. Z.; BOSI, M. L. M. Ética em pesquisa na dinâmica do campo científico: desafios na construção de diretrizes para ciências humanas e sociais. Ciência \& Saúde Coletiva, Rio de Janeiro, v. 20, n. 9, p. 2615-2624, 2015.

GUERRIERO, I. C. Z.; MINAYO, M. C. S. Resolução no 510 de 7 de abril de 2016 que trata das especificidades éticas das pesquisas nas ciências humanas e sociais e de outras que utilizam metodologias próprias dessas áreas. Ciência \& Saúde Coletiva, Rio de Janeiro, v. 21, n. 8, p. 2619-2629, 2016.

GUERRIERO, I. C. Z.; MINAYO, M. C. S. A aprovação da Resolução CNS no 510/2016 é um avanço para a ciência brasileira. Saúde e Sociedade, São Paulo, v. 28, n. 4, p. 299-310, 2019.

HABERMAS, J. Teoría de la acción comunicativa. Madrid: Taurus Editorial; 1987.

HABERMAS, J. Dialética e Hermenêutica. Porto Alegre: L\&PM, 1987.

HEMMERSLEY, M. Against the ethicists: on the evils of ethical regulation. International Journal of Social Science Research Methodology, [S.I.], p. 211-225, jun. 2009.

HEIDEGGER, M. Ser e tempo. Petrópolis: Vozes e Editora Universitária São Francisco, 2005. 
HERTZ, R. Introduction. In: HERTZ, R. (ed.). Reflexivity \& Voice. Thousand Oaks: Sage; 1997. p. vii- xvii.

HUSSERL, E. A crise da humanidade europeia e a filosofia. Porto Alegre; EDIPUCRS, 2008.

ISRAEL, M; HAY, I. Research ethics for social scientists. Lonndon: Sage E., 2006.

KANDEL, L. Reflexões sobre o uso de entrevista, especialmente a não-diretiva e sobre pesquisas de opinião. Épistemologie Sociologique, [S.I.], v. 13, p. 25-46, 1972.

LÉVINAS, E. Totalidade e Infinito. Lisboa: Lisboa Edições 70, 1998.

LEVY-SRAUSS, C. Introdution à l'ouevre de Marcel Mauss. In: LEVY-SRAUSS, C. Marcel

Mauss: sociologie et anthropologie. Paris: Presses Universitaire de France; 1950. s.p.

MERLEAU-PONTY, M. Fenomenologia da percepção. São Paulo: Martins Fontes, 1999.

MINAYO, M. C. S.; GUERRIERO, I. C. Z. Reflexividade como ethos da pesquisa qualitativa. Ciência \& Saúde Coletiva, Rio de Janeiro, v. 19, n. 4, p. 1103-1112, 2014.

NATIONS, M. Corte a mortalha: o cálculo humano da morte infantil no Ceará. Rio de Janeiro: Editora Fiocruz, 2010.

NEVES, M. C. P. A fundamentação antropológica da bioética. Portal Médico, [S.I.], p. 1-9, jun. 2006. Available from: http//www.portalmedico.org.br/revista/bio1v4/fundament.html.

RESEARCH ETHICS COMMITTEES. Guidelines for Research Ethics in the Social Sciences, Humanities, Law and Theology. Oslo, 2019. Available in: https/www. forskningsetikk/Guidelines for Research Ethics in the Social Sciences, Humanities, Law and Theology.

RORTY, R. A filosofia e o espelho da natureza. Rio de Janeiro: Relume-Dumará, 1994.

SARTRE, J-P. O ser e o nada - Ensaio de ontologia fenomenológica. Petrópolis: Vozes, 1997.

SCHEPER-HUGHES, N. Death Without Weeping: The Violence of Everyday Life in Brazil. Berkeley: University of California Press, 1993.

SCHUTZ, A. Commonsense and scientific interpretations of human action. Hague: Martinus Nijhoff, 1987.

SOCIAL SCIENCE AND HUMANITIES RESEARCH ETHICS SPECIAL WORKING COMMITTEE. Giving voice to the spectrum, 2004. Canadá. Available in:

http://www.pre.ethics.gc.ca

THE INDIAN COMMITTEE FOR ETHICS IN SOCIAL SCIENCE RESEARCH IN

HEALTH. Ethical guidelines for social research in health 2001. Available in:

http//www.hsph.harvard.edu/bioethics/guidelines/ethical/html

THE NUREMBERG CODE OF 1947. The story of the Nazi medical crimes. New York: Schuman, 1949: xxiii-xxv. 
VICTORA, C.; OLIVEN, R.G.; ORO, A.P. Antropologia e ética: o debate atual no Brasil. Niterói: EDUFF; 2004.

WHITE, W. F. Sociedade de Esquina. Rio de Janeiro: Zahar; 2005.

WORLD MEDICAL ASSOCIATION. Helsinque Declaration, 1964. Available in: https://www.who.int/bulletin/archives/79(4)373.pdf

WORLD SCIENCE FORUM. Declaration on science, ethics and responsibility. UNESCO, Budapest, 2019. Available in; worldscienceforum.org/news/declaration-on-science-ethics-andresponsibility-1100.

Convite feito em: 10 de maio de 2021

Revisão feita em: 20 de novembro de 2021 